\title{
Effect of calving difficulty on the saleable milk yield of UK Holstein Friesian dairy cattle at different stages of lactation
}

A C Barrier, M P Coffey, M J Haskell

Scottish Agricultural College, Edinburgh, United Kingdom

Email: alice.barrier@sac.ac.uk

Introduction Calving difficulty, or dystocia, results in assistance being provided at delivery, thus increasing farm labour. In the dairy cow, dystocia is associated with stillbirth, but also leads to impaired fertility, reduced milk production and increased risks for peripartum diseases and culling (Mee, 2008). Thus, calving difficulty raises animal welfare and economic issues. Considering milk yield, it is not clear how long the adverse effect on production lasts. Studies usually consider the milk produced by animals with full lactations but the saleable milk production of the whole herd, regardless of each cow having achieved a full lactation, might be more representative of the real losses that producers incur. The objective of this study was to investigate how various degrees of calving difficulty would alter the production of saleable milk in UK dairy cattle over different stages of their subsequent lactation.

Materials and methods The calving difficulty scores and the subsequent milk production of Holstein Friesian cattle having calved on the SAC experimental herd (Edinburgh, UK) between 1990 and 2000 inclusive were extracted from the farm database. The calving difficulty was scored as follows: no assistance (N), Farm assistance without and with malpresentation (FN/FM), Veterinarian assistance without/with malpresentation (VN/VM) and caesarean section (VC). Cows were conventionally milked twice a day and their individual daily milk yields were recorded automatically at milking conditional on the milk being sent to the tank for sale. Cumulative saleable milk yield (1) was calculated at 30, 60, 90 and 300 days in milk (DIM) unconditional on the animal having achieved the lactation stage of interest. Lactation cumulative yields were obtained on the basis of the real lactation length achieved by the animal. Animals were from two genetic groups (S: animals selected toward greater milk solids production; C: animals selected to be UK average) and split over 3 diet types (H: high forage diet; L: low forage diet; NT: standard high concentrate diet type). Linear mixed models were used following a REML procedure in Genstat to analyse the various cumulative milk yields. In the fixed effects, parity of the cow (primiparous vs multiparous), genetic group*diet, calving season (Summer: April to September; Winter: October to March) and calving ease were fitted as factors and calving year as a covariate. The random model included the cow identity nested within its sire.

Results Cows experiencing FN and VN scores had decreased cumulative saleable milk production throughout their lactation compared to non assisted animals ( $\mathrm{P}<0.05$; Table 1$)$. Losses occurred as early as $30 \mathrm{DIM}(\mathrm{FN}:-5.2 \%$; VN: $-8.8 \%)$ and persisted until the end of the lactation (FN: $-8.1 \%$; VN: $-12.5 \%$ ). No losses were found for FM, VM and VC dams. As shown by previous research, parity, genetic group, diet, season and calving year affected the saleable yields. Those effects were found at all stages of the lactation except at 30 DIM for calving season and at both 300 DIM and over the lactation for genetic group*diet.

Table 1 Estimated means of the cumulative marketable milk yields (1) over subsequent lactation of dairy cattle following different degrees of calving difficulty. Number of lactations available for analysis for each calving ease score is given in brackets.

\begin{tabular}{|c|c|c|c|c|c|c|c|c|}
\hline \multirow[b]{2}{*}{$\begin{array}{l}\text { Cumulative } \\
\text { Yield (1) }\end{array}$} & \multicolumn{2}{|c|}{ Calving difficulty } & \multirow[b]{2}{*}{$\begin{array}{l}\text { FM } \\
(n=74)\end{array}$} & \multirow[b]{2}{*}{$\begin{array}{l}\mathrm{VN} \\
(\mathrm{n}=38)\end{array}$} & \multirow[b]{2}{*}{$\begin{array}{l}\text { VM } \\
(n=30)\end{array}$} & \multirow[b]{2}{*}{$\begin{array}{l}\mathrm{VC} \\
(n=15)\end{array}$} & \multirow[b]{2}{*}{ s.e } & \multirow[b]{2}{*}{$P$ value } \\
\hline & $\begin{array}{l}\mathrm{N} \\
(\mathrm{n}=1855)\end{array}$ & $\begin{array}{l}\mathrm{FN} \\
(\mathrm{n}=227)\end{array}$ & & & & & & \\
\hline 30 DIM & $647^{a}$ & $613^{b}$ & $635^{a, b}$ & $590^{b}$ & $606^{\mathrm{a}, \mathrm{b}}$ & $572^{a, b}$ & 22.5 & $* *$ \\
\hline 60 DIM & $1502^{\mathrm{a}}$ & $1430^{b}$ & $1479^{a, b}$ & $1384^{\mathrm{a}, \mathrm{b}}$ & $1425^{a, b}$ & $1377^{\mathrm{a}, \mathrm{b}}$ & 50.3 & $*$ \\
\hline 90 DIM & $2320^{\mathrm{a}}$ & $2218^{b}$ & $2304^{\mathrm{a}, \mathrm{b}}$ & $2110^{b}$ & $2222^{a, b}$ & $2165^{\mathrm{a}, \mathrm{b}}$ & 78.5 & $*$ \\
\hline 300 DIM & $6375^{a}$ & $5859^{\mathrm{b}, \mathrm{c}}$ & $6377^{\mathrm{a}, \mathrm{c}}$ & $5520^{b}$ & $6003^{a, b}$ & $5722^{a, b}$ & 264.0 & $* * *$ \\
\hline lactation & $6857^{a}$ & $6305^{\mathrm{b}, \mathrm{c}}$ & $6931^{\mathrm{a}, \mathrm{c}}$ & $5999^{b}$ & $6578^{a, b}$ & $6221^{\mathrm{a}, \mathrm{b}}$ & 320.0 & $* *$ \\
\hline
\end{tabular}

Within a row, means without a common letter differ. s.e : pooled standard error of the mean. ${ }^{*}: P<0.05 ; * *: \mathrm{P}<0.01 ; * * *$ : $\mathrm{P}<0.001$

Conclusion Decreased cumulative saleable milk production was found for cows needing farm staff or veterinarian assistance but only if the calf was not malpresented (FN and VN scores). Not only did these losses occur in the early stages of the lactation but they persisted over time and appeared to be higher by the end of the lactation. Therefore, our results support the idea that calving assistance triggers long-term saleable milk production losses for the dairy producer. The lack of effect seen for VM and VC scores is probably due to the low number of animals available whereas failure to find an effect for FM might be due to the farm staff assisting more quickly when malpresentation becomes obvious. Lower saleable milk production may be the result of decreased milk yields by the cow herself as well as higher milk wastage due to a subsequent poorer health. Further analyses into the health of the cow during the relevant lactation would be needed to investigate that hypothesis.

Acknowledgements The authors are grateful to Defra, the Scottish Government, CIS, Cogent, DairyCo, Genus, Holstein UK and NMR for funding as well as to farm and technical staff for data collection over those years.

Reference

Mee, J. 2008. Prevalence and risk factors for dystocia in dairy cattle: a review. Veterinary Journal 176, 93-101. 